DOI: $10.4274 /$ jarem.galenos.2021.22932

J Acad Res Med 2021;11(1):81-85

\title{
The Diagnostic Value of Free Androgen Index in Obese Adolescent Females with Idiopathic Hirsutism and Polycystic Ovary Syndrome
}

\author{
(1) Elif Sağsak1, (1) Melikşah Keskin2, (1) Semra Çetinkaya2, (1) Şenay Savaş Erdeve2, (1) Zehra Aycan2 \\ 1 University of Health Sciences Turkey, Gaziosmanpaşa Training and Research Hospital, Clinic of Pediatric Endocrinology, İstanbul, Turkey \\ 2University of Health Sciences Turkey, Dr. Sami Ulus Maternity and Children's Health and Diseases Training and Research Hospital, Clinic of \\ Pediatric Endocrinology, Ankara, Turkey
}

Cite this article as: Sağsak E, Keskin M, Çetinkaya S, Savaş Erdeve Ş, Aycan Z. The Diagnostic Value of Free Androgen Index in Obese Adolescent Females with Idiopathic Hirsutism and Polycystic Ovary Syndrome. J Acad Res Med 2021;11(1):81-85

\begin{abstract}
Objective: The free androgen index (FAl) is the ratio between total testosterone and sex hormone binding globulin (SHBG), and it has been proposed as a marker. FAl is increasingly used in the definitive diagnosis of patients with hyperandrogenism. Although the reference range of FAl in adult females has been identified, there are no adequate studies on the reference range for adolescent girls. We determined the diagnostic value of FAI in adolescent girls diagnosed with obesity, idiopathic hirsutism $(\mathrm{IH})$ and polycystic ovary syndrome (PCOS).

Methods: Patients aged 12 to 21 years and diagnosed with obesity, IH and PCOS were included in the study. FAl was found by calculating the ratio of total testosterone to SHBG.

Results: According to receiver-operating characteristic (ROC) analysis results, FAl level under 3.45 indicated that the participants were healthy. ROC analysis was also used to determine the usefulness of FAl in distinguishingbetween healthy participants and those diagnosed withPCOS, obesity, IH. It was determined that patients with FAl above 6.15 should be evaluated for PCOS.

Conclusion: We concluded that FAl is a reliable marker to identify and followup patients with hyperandrogenism and the reference values we found in our study can be used in clinical practice.

Keywords: Free androgen index, obesity, idiopatic hirsutism, PCOS
\end{abstract}

\section{INTRODUCTION}

Androgen excess is one of the most common endocrine disorders of reproductive-aged women, affecting approximately $7 \%$ of this population (1-3). Androgen excess results in the development of androgenic features in the affected women with the development of hirsutism, androgenic alopecia, acne and ovulatory dysfunction, and if it is extreme and prolonged, it could even lead to virilisation and masculinisation (4). Androgen excess is the cardinal underlying phenomenon in various disorders in females, particularly polycystic ovary syndrome (PCOS), idiopathic

ORCID IDs of the authors: E.S. 0000-0001-7121-1575; M.K. 0000-0002-2713-3618; S.Ç. 0000-0003-3974-2872; S..S.E. 0000-0002-4164-5089; Z.A. 0000-0003-4584-2976.

Corresponding Author/Sorumlu Yazar: Elif Sağsak,

E-mail: caliskanozturk@yahoo.com
Received Date/Geliş Tarihi: 21.01.2021 Accepted Date/Kabul Tarihi: 02.03 .2021

CC Copyright 2021 by University of Health Sciences Turkey, Gaziosmanpaşa Training and Research Hospital. Available on-line at www.jarem.org 
hirsutism $(\mathrm{IH})$, congenital adrenal hyperplasia and ovarian/adrenal neoplasms, as well as insulin resistance/obesity. Increased insulin in obese patients stimulates ovarian androgen production driven by increased luteinising hormone secretion and contributes to hyperandrogenism. Free or bioactive testosterone is responsible for the pathogenesis of androgen excess status. Nevertheless, it is difficult to identify hyperandrogenism in the laboratory in children and adolescents and associate it with clinical findings. However, there is no consensus regarding what serum level is significantly higher and when treatment should be started $(5,6)$. Simple and practical criteria/methods, therefore, need to be developed.

The free androgen index (FAl) is the ratio between total testosterone and sex hormone binding globulin (SHBG), and it has been proposed as a marker. FAl is increasingly used in the definitive diagnosis of patients with hyperandrogenism (5). Although the reference range of the FAl in adult females has been identified, there are no adequate studies on the reference range for adolescent girls (7). In our study, we determined the diagnostic value of FAl in adolescent girls diagnosed with obesity, $\mathrm{IH}$ and PCOS.

\section{METHODS}

Patients aged 12 to 21 years and diagnosed with obesity, $\mathrm{IH}$ or PCOS in the pediatric endocrinology clinic of our hospital were included in the study.

\section{Definition of the groups:}

The obesity group consisted of patients with a body mass index (BMI) of $>2$ standard deviation score (SDS).

$\mathrm{IH}$ group consisted of patients with $\mathrm{IH}$ who had a FerrimanGallwey score 8 or more and no other reason for the hirsutism.

The PCOS group consisted ofpatients who met all of the PCOS Amsterdam 2013 diagnostic criteria for adolescents, which are as follows (8):

1- Oligomenorrhea or primary amenorrhea present 2 years after menarche,

2- At least one ovary of a volume $>10 \mathrm{~mL}$,

3- Presence of a clinical and biochemical hyperandrogenism (diagnosis criteria for clinical hyperandrogenism: FerrimanGallwey score of 8 or more; diagnostic criteria for biochemical hyperandrogenism: Total testosterone level $>51 \mathrm{ng} / \mathrm{dL}$ ).

The control group consisted of healthy adolescent females with a normal weight, without any clinical or laboratory signs of hyperandrogenism, and not using any medication affecting the androgen metabolism.

\section{Laboratory studies:}

Blood samples were drawn in the first week of the menstrual cycle. Total testosterone and SHBG were studied from the sera. All tests were performed at the biochemistry department of our hospital. Total testosterone was measured by solid-phase competitive chemiluminescent enzyme immunoassay, using the ADVla
Centaur-XP instrument (Siemens, Germany), and SHBG was measured by radioimmunoassay, using Beckman Coulter (USA).

FAl and homeostasis model assessment-estimated insulin resistance (HOMA-IR) calculation:

FAl was calculated according to the formula: [total testosterone $(\mathrm{nmol} / \mathrm{L}) / \mathrm{SHBG} \quad(\mathrm{nmol} / \mathrm{L})] \times 100 \quad$ (5). Total testosterone was measured in $\mathrm{ng} / \mathrm{dL}$, so $\mathrm{ng} / \mathrm{dL}$ was converted to $\mathrm{nmol} / \mathrm{L}$ (ng/ $\mathrm{dL} \times 0.03470$ : $\mathrm{nmol} / \mathrm{L})$. HOMA-IR was calculated according to the following formula: fasting blood glucose $(\mathrm{mg} / \mathrm{dL}) \times$ fasting blood insulin (IU/mL)/405 (9).

\section{Statistical Analysis}

Descriptive statistics for the study variables were presented as median, mean, standard deviation and minimum and maximum values. The Kruskal-Wallis test was used to compare the control and patient groups. The cut-off value for the hormone was determined by receiver-operating characteristic (ROC) analysis. Statistical significance levels were considered at 5\%. The SPSS (ver. 13) statistical programme was used for all statistical computations.

The study was approved by the Ethical Committee of Dr. Zekai Tahir Burak Women's Health Training and Research Hospital, and conducted according to the principles of the Declaration of Helsinki. The approval number is 23/2014 (approval date: 15.04.2014). All parents/guardians of the children provided written informed consent before the children were included in the study.

\section{RESULTS}

The patients' ages, BMI, BMI-SDS, HOMA-IR, total testosterone, SHBG and FAI values are shown in Table 1. There were differences in ages between the four groups. The PCOS group consisted of patients older than those in the obesity and control groups. The ages of patients in $\mathrm{IH}$ group were similar to those in other groups. As expected, BMI and BMI-SDS were higher in the obesity group than the other groups. In addition, BMI and BMI-SDS were found to be higher in the PCOS and IH groups than the control group. While HOMA-IR was similar in obesity, IH and PCOS groups, it was higher in these groups than the control group. While serum total testosterone levels were the highest in the PCOS group (total testosterone: $84.3 \pm 22.9 \mathrm{ng} / \mathrm{dL}$ ), serum total testosterone levels were $68.5 \pm 16.3,60.5 \pm 10.6$ and $37.1 \pm 12.6 \mathrm{ng} / \mathrm{dL}$ in $\mathrm{IH}$, obesity and control groups, respectively. There was no difference in testosterone levels between $\mathrm{IH}$ and obesity groups. Testosterone levels were lower in the control group than the other groups. While serum SHBG levels were similar in obesity, IH and PCOS groups, it was higher in the control group.

ROC analysis was used to determine the usefulness of FAI in distinguishing healthy adolescents (control group) from other groups. According to ROC analysis, the area under the curve (AUC) was found to be $0.930 \pm 0.22$. The sensitivity and specificity values for $\mathrm{FAl}$, whose cut-off value was 3.45 , were found to be $90 \%$ and $84 \%$, respectively. Accordingly, FAl under 3.45 indicated that the participants were healthy (Figure 1). 


\begin{tabular}{|c|c|c|c|c|c|}
\hline & $\begin{array}{l}\text { Obesity } \\
n=26\end{array}$ & $\begin{array}{l}\mathrm{IH} \\
\mathrm{n}=26\end{array}$ & $\begin{array}{l}P C O S \\
n=20\end{array}$ & $\begin{array}{l}\text { Control } \\
n=72\end{array}$ & $p$ \\
\hline Age (years) & $\begin{array}{l}14.6 \pm 2.02^{b} \\
12-18\end{array}$ & $\begin{array}{l}15.6 \pm 1.56^{a b} \\
12-18\end{array}$ & $\begin{array}{l}16 \pm 1.58^{a} \\
13.5-19\end{array}$ & $\begin{array}{l}14.9 \pm 1.72^{b} \\
12-18\end{array}$ & 0.040 \\
\hline BMI $\left(\mathrm{kg} / \mathrm{m}^{2}\right)$ & $\begin{array}{l}31.7 \pm 4.1^{\mathrm{a}} \\
26-40.68\end{array}$ & $\begin{array}{l}24.5 \pm 3.88^{b} \\
17.3-31.60\end{array}$ & $\begin{array}{l}25.4 \pm 4.96^{b} \\
18.2-34.9\end{array}$ & $\begin{array}{l}21 \pm 2.82^{c} \\
15.7-27.34\end{array}$ & 0.01 \\
\hline BMI-SDS & $\begin{array}{l}2.8 \pm 0.69^{a} \\
2-4.33\end{array}$ & $\begin{array}{l}1.1 \pm 1.1^{b} \\
-1.20-3.5\end{array}$ & $\begin{array}{l}1.2 \pm 1.4^{b} \\
-1.60-3.98\end{array}$ & $\begin{array}{l}-0.1 \pm 1.2^{c} \\
-1.80-1.91\end{array}$ & 0.01 \\
\hline HOMA-IR* & $\begin{array}{l}3.89 \pm 1.7^{\mathrm{a}} \\
1.44-8.48\end{array}$ & $\begin{array}{l}3.06 \pm 2.2^{\mathrm{a}} \\
0.80-11.20\end{array}$ & $\begin{array}{l}3.19 \pm 1.3^{a} \\
1.16-6.60\end{array}$ & $\begin{array}{l}1.7 \pm 0.56^{b} \\
0.90-3.5\end{array}$ & 0.01 \\
\hline Total testosterone (ng/dL) & $\begin{array}{l}60.5 \pm 10.6^{b} \\
51-89.10\end{array}$ & $\begin{array}{l}68.5 \pm 16.3^{b} \\
52.97-112.66\end{array}$ & $\begin{array}{l}84.3 \pm 22.9^{a} \\
53.10-142\end{array}$ & $\begin{array}{l}37.1 \pm 12.6^{c} \\
10-50\end{array}$ & 0.01 \\
\hline SHBG (nmol/L) & $\begin{array}{l}23.9 \pm 14.8^{b} \\
6.71-66.71\end{array}$ & $\begin{array}{l}34.8 \pm 16^{b} \\
7.35-77.40\end{array}$ & $\begin{array}{l}28.6 \pm 18.1^{b} \\
9.54-75.68\end{array}$ & $\begin{array}{l}56.1 \pm 22.6^{a} \\
17.44-10.2\end{array}$ & 0.01 \\
\hline FAI (\%) & $\begin{array}{l}9.9 \pm 6.4^{a} \\
1.70-27.30\end{array}$ & $\begin{array}{l}7.7 \pm 6^{\mathrm{a}} \\
1.80-29.70\end{array}$ & $\begin{array}{l}14.4 \pm 9.6^{\mathrm{a}} \\
3.40-43.0\end{array}$ & $\begin{array}{l}2.4 \pm 1.3^{b} \\
0.20-6.40\end{array}$ & 0.01 \\
\hline
\end{tabular}

*HOMA-IR was calculated according to the following formula: fasting blood glucose (mg/dL) xfasting blood insulin (IU/mL)/405 (9).

a,b,c Statistically different groups represented by different letters $(p<0.05)$. IH: idiopathic hirsutism, PCOS: polycystic ovary syndrome, BMI: body mass index, SDS: standard deviation score, HOMA-IR: homeostasis model assessment-estimated insulin resistance, SHBG: sex hormone binding globulin, FAl: free androgen index

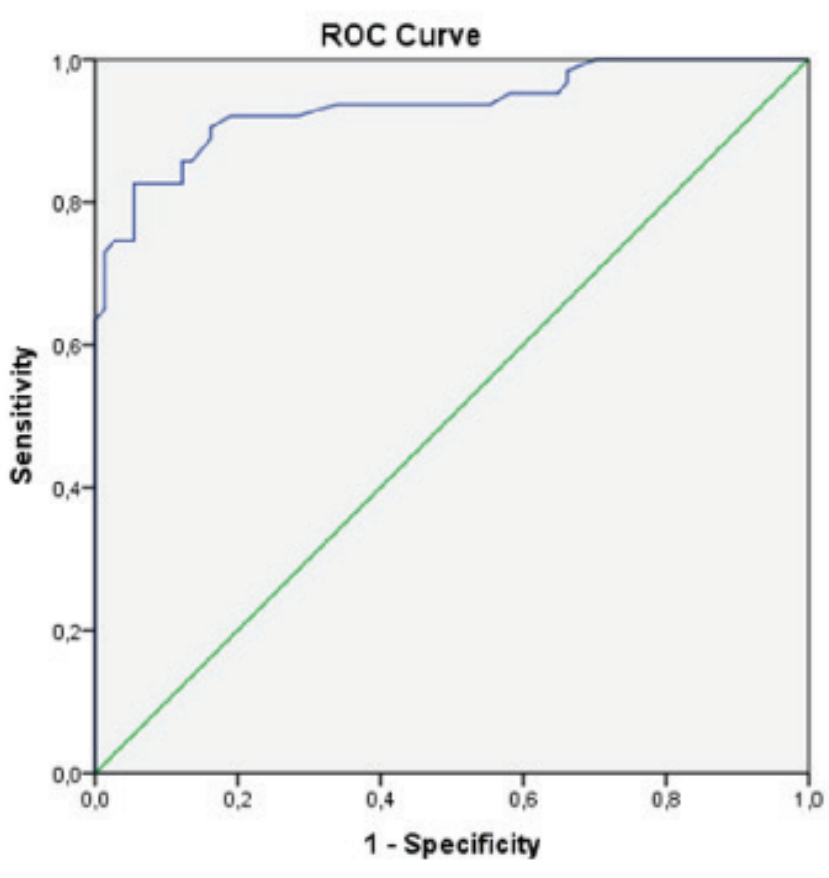

Diagonal segments are produced by ties.

Figure 1. ROC analysis curve detecting the usefulness of free androgen index in distinguishing between the control group and other groups

ROC: receiver-operating characteristic

$\mathrm{ROC}$ analysis was also used to determine the usefulness of FAI in distinguishing between patients in PCOS group and those in obesity and $\mathrm{IH}$ groups. According to ROC analysis, AUC was found to be $0.88 \pm 0.35$. Sensitivity and specificity values for FAl with a cut-off value under 6.15 were found to be $89 \%$ and $77 \%$, respectively. Therefore, it was determined that patients whose FAI was above 6.15 should be evaluated for PCOS (Figure 2).

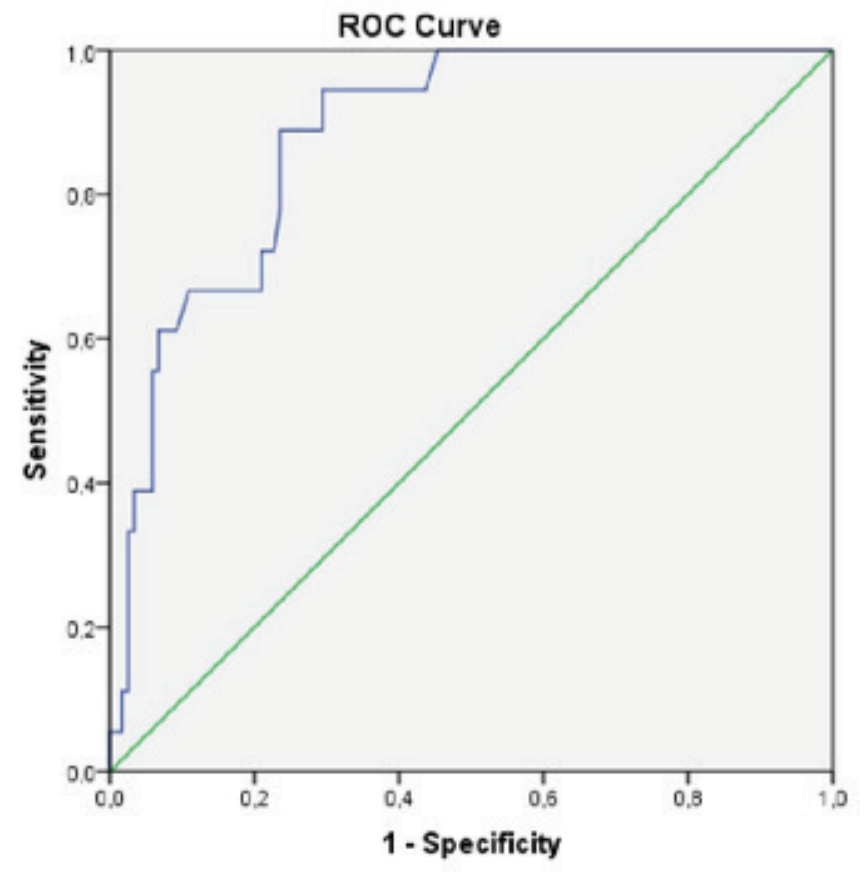

Diagonal segments are produced by ties.

Figure 2. ROC analysis curve detecting the usefulness of free androgen index in distinguishing between polycystic ovary syndrome group and other groups

ROC: Receiver-operating characteristic

In the obesity group, there was a positive correlation between FAI and BMI ( $r=0.426 ; p=0.048)$ and HOMA-IR $(r=0.530 ; p=0.011)$.

\section{DISCUSSION}

Androgen excess is the cardinal underlying phenomenon in various disorders in females. Free or bioactive testosterone is responsible for the pathogenesis of androgen excess status. It is 
difficult to identify hyperandrogenism in the laboratory in children and adolescents and associate it with clinical findings.

In literature, studies on FAI were commonly conducted on adult females. In a study, Pinola et al. (7) found that FAl was $2.1 \pm 1.3$ in adult females, whereas it was $4.4 \pm 3.8$ in females with PCOS. In females aged 18-24 years old, healthy females had an FAI of 1.9 \pm 1.1 , while females diagnosed with PCOS had an FAl of

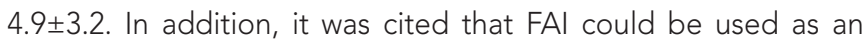
important parameter to diagnose PCOS in all age groups. Our study evaluated adolescentsin the age range of 12-21 years, and it was found that FAl with a cut-off value $<3.45$ indicated that the participants were healthy and a cut-off value $>6.15$ indicated that participants should be evaluated for PCOS. These values had a high sensitivity and specificity.

A study from China reported FAl reference range of 0.7-6.4 in 444 patients aged 20-46 years selected from a group of 1,526 females after excluding disorders influencing the androgen level. The $5^{\text {th }}$ percentile FAl value was 0.8 and the $95^{\text {th }}$ percentile value was 6.7 for patients aged 20-28 years. The same study found FAl to be negatively correlated with age. They stated that FAl was higher in patients diagnosed with hirsutism and PCOS than in the healthy population, and BMI and FAl had a positive correlation (10). Moreover, FAl increased in insulin excess $(11,12)$.

In our study, similar to previous studies, a positive correlation was found between FAI and HOMA-IR in the obesity group. In a previous study reported in Mexico, FAl of 83 healthy nonobese females was $5.3 \pm 3.8$, while that of 238 obese females was $8.5 \pm 5.3$ (13).

Few studies on FAl in adolescents are available. A study by lbanez et al. (14) reported that normal FAl in healthy adolescents aged $14-18$ years was $<5$. A Canadian study by Raizman and Quinn (15) investigated FAl in 66 females aged 9-14 years. The lowest value was 0.12 and the highest value was 2.63. In healthy females aged 14-19 years, the lowest and highest values were 0.59 and 6.5, respectively.

The age range of our control group was 12-18 years. The lowest and highest FAl values were 0.2 and 6.4 , respectively. These values are close to the values found by Raizman and Quinn (15). In a study by Liimatta et al. (16), FAl was 0.38 (0.32-0.53) in 97 healthy females younger than eight years old and 2.93 (2.33-5.94) in 16 healthy adolescent females.

Few studies investigating FAI values in adolescents with PCOS are available. A study by Yetim et al. (17) reported that FAI was 6.75 (0.97-23.66) in the PCOS group consisting of 53 adolescent females and $3(0.22-36.65)$ in the control group. These values are consistent with ours, with a cut-off value of 6.15 , indicating a diagnosis of PCOS, and 3.45 in healthy adolescents.

\section{Study Limitations}

The limitation of this study is the small number of participants.

\section{CONCLUSION}

In our study, we determined that an FAl with a cut-off value of 6.15 indicated a diagnosis of PCOS and 3.45 in healthy adolescents and these valuescan be used in practice. We concluded that FAl is a reliable marker to identify and follow-up patients with hyperandrogenism in clinical situations with elevated androgen levels and that the reference values we found in our study can be used in clinical practice.

Ethics Committee Approval: The study was approved by the Ethical Committee of Dr. Zekai Tahir Burak Women's Health Training and Research Hospital (approval number: 23/2014, approval date: 15.04.2014).

Informed Consent: All parents/guardians of the children provided written informed consent before the children were included in the study.

Peer-review:Externally peer-reviawed.

Authorship Contributions: Concept - E.S., Z.A.; Design - E.S., S.Ç., M.K., S.S.E.; Data Collection or Processing - E.S., M.K.; Analysis or Interpretation - E.S., Ş.S.E., S.Ç., Z.A.; Literature Search - E.S., M.K.; Writing - E.S.

Conflict of Interest: No conflict of interest was declared by the authors.

Financial Disclosure: The authors declared that this study received no financial support.

\section{REFERENCES}

1. Knochenhauer ES, Key TJ, Kahsar-Miller M, Waggoner W, Boots LR, Azziz R. Prevalence of the polycystic ovary syndrome in unselected black and white women of the southeastern United States: a prospective study. J Clin Endocrinol Metab 1998; 83: 3078-82.

2. Diamanti-Kandarakis E, Kouli CR, Bergiele AT, Filandra FA, Tsianateli TC, Spina GG, et al. A survey of the polycystic ovary syndrome in the Greek island of Lesbos: hormonal and metabolic profile. J Clin Endocrinol Metab 1999; 84: 4006-11.

3. Asuncion M, Calvo RM, San Millan JL, Sancho J, Avila S, EscobarMorreale HF. A prospective study of the prevalence of the polycystic ovary syndrome in unselected Caucasian women from Spain. J Clin Endocrinol Metab 2000; 85: 2434-8.

4. Azziz R, Sanchez LA. Androgen excess in women: experience with over 1000 consecutive patients. J Clin Endocrinol Metab 2004; 89: 453-62.

5. Kindi M, Essry F. Validity of serum testosterone, free androgen index, and calculated free testosterone in women with suspected hyperandrogenism. Oman Med J 2012; 27: 471-4.

6. Anthony Weil P. The Diversity of The Endocrine System. In: Murray RK, Bender DA, Botham KM, Kennekky PJ, Rodwell VW, Anthony Weil P, (eds). Harper's Illustrated Biochemistry. 28th ed. New York: McGraw-Hill; 2009. p.250-85.

7. Pinola P, Piltonen TT, Puurunen J, Vanky E, Sundström-Poromaa I, Stener-Victorin $E$, et al. Androgen profile through life in women with polycystic ovary syndrome: A nordic multicenter collaboration study. J Clin Endocrinol Metab 2015; 100: 3400-7.

8. Fauser BC, Tarlatzis BC, Rebar RW, Legro RS, Balen AH, Lobo R, et al. Consensus on women's health aspects of polycystic ovary syndrome (PCOS): the Amsterdam ESHRE/ASRM-Sponsored 3rd PCOS Consensus Workshop Group. Fertil Steril 2012; 97: 28-38.

9. Wallace TM, Levy JC, Matthews DR. Use and abuse of HOMA modeling. Diabetes Care 2004; 27: 1487-95.

10. Zhou Z, Ni R, Hong Y. Defining hyperandrogenaemia according to the free androgen index in Chinese women: A cross-sectional study. Clin Endocrinol 2012; 77: 446-52.

11. Eden JA, Carter GD, Jones J, Alaghband-Zadeh J, Pawson M. Factor influencing the free androjen Index in a group of subfertile women with normal ovaries. Ann Clin Biochem 1988; 25: 350-3.

12. Maturana MA, Spritzer PM. Association between hyperinsulinemia and endogenous androgen levels in peri and post menopausal women. Metabolism 2002; 51: 238-43. 
13. Reyes-Munoz E, Ortega-Gonzalez C, Martinez-Cruz N, Arce-Sánchez L, Estrada-Gutierrez G, Moran C, et al. Association of obesity and overweight with the prevalence of insulin resistance, pre-diabetes and clinical-biochemical characteristics among infertile Mexican women with polycystic ovary syndrome: a cross-sectional study. BMJ Open 2016; 22; 6: e012107. doi: 10.1136/bmjopen-2016-012107.

14. Ibanez L, Potau N, Marcos MV. Treatment of hirsutism, hyperandrogenism, oligomenorrhea, dyslipidemia, and hyperinsulinism in nonobese, adolescent girls: effects of flutamide. J Clin Endocrinol Metab 2000; 85: $3251-5$.
15. Raizman J, Quinn F. Pediatric reference intervals for calculated free testosterone, bioavailabl testosterone and androgen index in the caliper cohort. Clin Chem Med 2015; 53: e239-43. doi: 10.1515/cclm-2015-0027.

16. Liimatta J, Laakso S, Utriainen P. Serum androgen bioactivity is low in children with premature adrenarche. Pediatr Res 2014; 75: 645-50.

17. Yetim A, Yetim Ç, Baş F, Erol OB, Çığ G, Uçar A, et al. Anti-Müllerian Hormone and Inhibin-A, but not Inhibin-B or Insulin-Like Peptide-3, may be used as surrogates in the diagnosis of polycystic ovary syndrome in adolescents: Preliminary Results. J Clin Res Pediatr Endocrinol 2016; 8: 288-97. 